\title{
Commentary
}

\author{
Pablo Teta*
}

\section{The usage of subgenera in mammalian taxonomy}

https://doi.org/10.1515/mammalia-2018-0059

Received April 4, 2018; accepted July 6, 2018; previously published online July 28, 2018

\begin{abstract}
In this note, I discuss the advantages of the usage of subgenera as a practical taxonomic rank in mammalian taxonomy. Use of this category preserves traditional usage, reduces nomenclatural instability and avoids unnecessary change of names. Subgenera are useful to label diagnosable clades of closely related species, especially in morphologically and ecologically diverse monophyletic genera, without alteration of traditional binomial usage. Contrary to informal names such as "divisions" or "groups", subgenera are governed by the rules of the International Commission on Zoological Nomenclature (ICZN), having usage constrained (and stability promoted) by typification and priority.
\end{abstract}

Keywords: Linnaean categories; nomenclatural stability; phylogenies; rank-based nomenclature; subgenus.

Molecular techniques have greatly enhanced our ability to recognize clades, leading some to propose new genera for these groupings (e.g. Weksler et al. 2006, Byrne et al. 2016). This has had the effect of disrupting traditional classification and thus communication among biologists. In some cases, the resurrection or the creation of new generic entities is mostly beyond doubt (e.g. Weksler et al. 2006). However, a more complex situation arises when well-supported clades, involving a variety of morphotypes and distinctive evolutionary and ecological variants, are included under a single monophyletic nominal genus, producing a classification of dubious heuristic value (Wheeler 2004, Ford 2006).

The subgenus is a category recognized in zoological nomenclature intermediate between the genus and the species (Dubois 2007, 2008). Its use varies greatly from one group of organisms to another (Winston 1999). Its application has been criticized, being for some researchers "an obscure rank at best" (Frost 2018). For other authors, the nature of higher-category taxa (i.e. taxa above the

\footnotetext{
*Corresponding author: Pablo Teta, División Mastozoología, Museo Argentino de Ciencias Naturales "Bernardino Rivadavia”, Avenida Ángel Gallardo 470, C1405DJR Buenos Aires, Argentina, e-mail: antheca@yahoo.com.ar
}

species level) is inevitably subjective (e.g. Laurin 2010, but see Humphreys and Barraclough 2014), an issue that is not my intention to discuss here. In turn, I want to debate the usage of subgenera as a practical taxonomic rank, which maintains traditional usage but also allows the storage and retrieval of systematic information. My defense of the subgenera is best explained by the following points:

1. A main goal of the zoological nomenclature is to promote nomenclatural stability whenever possible, in order to help a more efficient communication among scientists. The use of subgenera is in agreement with this goal as the recognition of this category preserves traditional usage and avoids unnecessary change of genera (e.g. Giarla et al. 2010, Voss et al. 2014, Teta et al. 2016, Pavan and Voss 2016).

2. Group names represent a nested system for information storage and retrieval (Mayr 1969, Benton 2007), being not only referents for sets of taxa (e.g. De Queiroz 2007). A main strength of the Linnaean nomenclature is its value in generating predictions, which depends on assigning specific coordinate rankings for coordinate entities (Patterson and Upham 2014). Accordingly, subgenera are useful to label diagnosable clades of closely related species, without alteration of traditional binomial usage.

3. The use of informal names for well-supported clades within monophyletic taxa, such as "divisions", "sections" or "groups", has several inconveniences. On one hand, informal group names do not denote hierarchical relationships [as Voss et al. (2014) expressed: "do sections contain groups or do groups contain sections?"]; in fact “divisions”, “sections” or "groups” were variably used to refer both to well-defined clades within monophyletic genera (e.g. the olivacea and longipilis groups by Cañón et al. 2014 for Abrothrix Waterhouse 1837) or to group different, phylogenetically close and well-established genera [e.g. the five sections recognized by D'Elia (2003) for the tribe Akodontini]. On the other hand, informal names are not regulated, leading to some chaos in its application and use. On the contrary, subgenera are governed by the rules of the International Commission on Zoological Nomenclature (ICZN) (1999), having its usage constrained (and stability promoted) by typification and priority (cf. Voss et al. 2014). 
A good example of the points previously discussed is given by the recent taxonomic history of the bat genus Lasiurus Gray 1831. This monophyletic genus was recently split, based mostly on molecular data and external differences in coat color (Baird et al. 2015), into three different genera, namely Aeorestes Fitzinger 1870, Dasypterus Peters 1871, and Lasiurus s.s. However, as was noted by Ziegler et al. (2016) and Novaes et al. (2018), the use of a subgeneric classification would be sufficient to recover the phylogenetic information presented by Baird et al. (2015). Recognizing the well-established monophyletic genus Lasiurus, with Aeorestes and Dasypterus as subgenera within it, provides information about the taxonomic position of different species within it and also maintains nomenclatural stability. In this case, the genus name Lasiurus is informative about the close relationship that exists between the subgenera Aeorestes, Dasypterus and Lasiurus, which is supported by molecular and morphological evidence (Ziegler et al. 2016, Novaes et al. 2018), whereas the subgeneric names, Aeorestes, Dasypterus and Lasiurus, are indicative of different evolutionary lineages within Lasiurus s.l. [e.g. Lasiurus (Aeorestes) cinereus and Lasiurus (Aeorestes) villosissimus are more closely related to each other than either are to Lasiurus (Dasypterus) ega]. Against the arguments expressed by Ziegler et al. (2016), Baird et al. (2015) claimed that "...subgenus distinction is almost never utilized in the literature and would quickly become obsolete...using subgeneric names would not solve the problem of having taxonomy under-represent the distinction among red, yellow, and hoary bats. In the past...literature that referred to that genus (i.e. Lasiurus) was ambiguous as to whether the study included red, yellow, or hoary bats... With the revised taxonomy, literature searches will become clearer as to which groups are being studied." I disagree with this opinion by the following: (i) there are several other recent taxonomic contributions guaranteeing the use of this taxonomical rank, that is far from being obsolete (e.g. Giarla et al. 2010, Voss et al. 2014, Pavan and Voss 2016, Teta et al. 2016, Gutiérrez and Marinho Filho 2017) and (ii) the use of a name such as Aeorestes, previously not employed for the species within Lasiurus (cf. Ziegler et al. 2016), surely complicates the searches, rather than facilitating them. For example, a search in GBIF (Global Biodiversity Information Facility; conducted on 28th February 2018) for Aeorestes cinereus villosissimus retrieved zero results against 65 for Lasiurus cinereus villosissimus.

In summary, I strongly encourage the use of subgenus, evaluating each case in particular. Even when some authors may not see it necessary to defend a valid and regulated taxonomic category such as the subgenus, numerous recent examples highlight the need to return to a more austere and stable taxonomy. For example, as was discussed by Gutiérrez and Marinho-Filho (2017), several recently erected or resurrected genera of Neotropical monkeys (e.g. Cheracebus, Leontocebus, Plectorocebus, Sapajus; Byrne et al. 2016, Rylands et al. 2016) could be regarded as subgenera within other well-recognized genera, in order to preserve nomenclatural stability.

Acknowledgments: I wish to acknowledge Guillermo D'Elía, who read a first version of this note. Different issues discussed here were debated with C. Cañón, J. Faivovich, G. Libardi, B. Patterson, U. Pardiñas and J. Torres.

\section{References}

Baird, A.B., J.K. Braun, M.A. Mares, J.C. Morales, J.C. Patton, C.Q. Tran and J.W. Bickham. 2015. Molecular systematic revision of tree bats (Lasiurini): doubling the native mammals of the Hawaiian Islands. J. Mammal. 96: 1255-1274.

Benton, M.J. 2007. The phylocode: beating a dead horse? Acta Palaeontol. Polon. 52: 651-655.

Byrne, H., A.B. Rylands, J.C. Carneiro, J.W. Lynch Alfaro, F. Bertuol, M.N.F. da Silva, M. Messias, C.P. Groves, R.A. Mittermeier, I. Farias, T. Hrbek, H. Schneider, I. Sampaio and J.P. Boubli. 2016. Phylogenetic relationships of the New World titi monkeys (Callicebus): first appraisal of taxonomy based on molecular evidence. Front. Zool. 13: 10. DOI 10.1186/s12983016-0142-4.

Cañón, C., D. Mir, U.F.J. Pardiñas, E.P. Lessa and G. D’Elía. 2014. A multilocus perspective on the phylogenetic relationships and diversification of rodents of the tribe Abrotrichini (Cricetidae: Sigmodontinae). Zool. Scr. 43: 443-454.

D’Elía, G. 2003. Phylogenetics of Sigmodontinae (Rodentia, Muroidea, Cricetidae), with special reference to the akodont group, and with additional comments on historical biogeography. Cladistics 19: 307-323.

De Queiroz, K. 2007. Species concepts and species delimitation. Syst. Biol. 56: 879-886.

Dubois, A. 2007. Phylogeny, taxonomy and nomenclature: the problem of taxonomic categories and of nomenclatural ranks. Zootaxa 1519: 27-68.

Dubois, A. 2008. Phylogenetic hypotheses, taxa and nomina in zoology. Zootaxa 1950: 51-86.

Ford, F. 2006. A splitting headache: relationships and generic boundaries among Australian murids. Biol. J. Linn. Soc. 89: 117-138.

Frost, D. 2018. Amphibian Species of the World: an online reference. Version 6 (28th March 2018). Electronic Database accessible at http://research.amnh.org/herpetology/amphibia/ index.html. American Museum of Natural History, New York, USA.

Giarla, T.C., R.S. Voss and S.A. Jansa. 2010. Species limits and phylogenetic relationships in the didelphid marsupial genus Thylamys based on mitochondrial DNA sequences and morphology. Bull. Am. Mus. Nat. His. 346: 1-67. 
Gutiérrez, E.E. and J. Marinho-Filho. 2017. The mammalian faunas endemic to the Cerrado and the Caatinga. ZooKeys 644: 105-157.

Humphreys, A.M. and T.G. Barraclough. 2014. The evolutionary reality of higher taxa in mammals. Proc. R Soc. Lond. B 281: 20132750.

ICZN. 1999. International Code of Zoological Nomenclature. International Trust for Zoological Nomenclature, London.

Laurin, M. 2010. The subjective nature of Linnaean categories and its impact in evolutionary biology and biodiversity studies. Contrib. Zool. 79: 131-146.

Mayr, E. 1969. Principles of systematic biology. McGraw-Hill, New York.

Novaes, R.L.M., S.T.G. Garbino, V.C. Cláudio and R. Moratelli. 2018. Separation of monophyletic groups into distinct genera should consider phenotypic discontinuities: the case of Lasiurini (Chiroptera: Vespertilionidae). Zootaxa 4379: 439-440.

Patterson, B.D. and N.S. Upham. 2014. A newly recognized family from the Horn of Africa, the Heterocephalidae (Rodentia: Ctenohystrica). Zool. J. Linn. Soc. 172: 942-963.

Pavan, S.E. and R.S. Voss. 2016. A revised subgeneric classification of short-tailed opossums (Didelphidae: Monodelphis). Am. Mus. Novit. 3868: 1-44.
Rylands, A.B., E.W. Heymann, J. Lynch Alfaro, J.C. Buckner, C. Roos, C. Matauschek, J.P. Boubli, R. Sampaio and R.A. Mittermeier. 2016. Taxonomic review of the New World tamarins (Primates: Callitrichidae). Zool. J. Linn. Soc. 177: 1003-1028.

Teta, P., C. Cañon, B. Patterson and U.F.J. Pardiñas. 2016. Phylogeny of the tribe Abrotrichini (Cricetidae, Sigmodontinae): integrating morphological and molecular evidence into a new classification. Cladistics 33: 153-182.

Voss, R.S., E.E. Gutiérrez, S. Solari, R.V. Rossi and S.A. Jansa. 2014. Phylogenetic relationships of mouse opossums (Didelphidae: Marmosa) with a revised subgeneric classification and notes on sympatric diversity. Am. Mus. Novit. 3817: 1-27.

Weksler, M., A.R. Percequillo and R.S. Voss. 2006. Ten new genera of oryzomyine rodents (Cricetidae: Sigmodontinae). Am. Mus. Novit. 3537: 1-29.

Wheeler, Q.D. 2004. Taxonomic triage and the poverty of phylogeny. Phil. Trans. R Soc. Lond. B 359: 571-583.

Winston, J.E. 1999. Describing species: practical taxonomic procedure for biologists. Columbia University Press, Columbia, USA.

Ziegler, A.C., F.G. Howarth and N.B. Simmons. 2016. A second endemic land mammal for the Hawaiian island: a new genus and species of fossil bat (Chiroptera: Vespertilionidae). Am. Mus. Novit. 3854: 1-52. 